\title{
Nanoscale Biomaterials for 3D printing
}

\author{
Akshay Bhatt ${ }^{1}$ and Anand Anbarasu ${ }^{1}$ \\ ${ }^{1}$ School of Biosciences and Technology, Vellore Institute of Technology, Vellore 632014, India
}

\begin{abstract}
Bio printing is an emerging tool for differentiating stem cells in $3 D$ patterns. This technique provides the platform for regeneration of organs and tissues in a systematic manner.The use of suitable biomaterial with its crosslinking property on addition of a cross linker gives the exact structure with which we can grow stem cells into a specific tissue or organ. There exists a number of conventional biomaterials used as bioinks for $3 D$ bioprinting and other biomedical applications, but due to its macro sized structure the applicability had been restricted to certain areas. In such cases nano-biomaterials play a key role in enhancing the physicochemical properties of existing biomaterials. Literature survey shows a wide range of conventional hydrogels available for printing and one can select these biomaterials according to the tissue to be regenerated. For example, regeneration of bone or cartilage requires relatively strong material and in such case soft materials will be inappropriate for the cells to differentiate into bone/cartilage tissue. Hence selection of biomaterial is one among the factors to be considered for tissue engineering. Here conventional biomaterials are not capable of fulfilling all the requirement of tissue engineering due its macro size and limited properties, therefore use of nanotechnology in the existing biomaterial can enhance the overall nature and bioactivity of the material. One more important factor influencing tissue regeneration is the use of bioinks. Bioinks not only protects the cells from external damage caused during fabrication but also helps in diffusion of nutrients and growth factors essential for cells differentiation and proliferation.As a prominent component of bio inks, hydrogels are commonly used in cell printing processes because of their low cytotoxicity and physical resemblance to the extracellular matrix (ECM). The review mainly focuses on the nanobiomaterials made from synergistic combinations of nanomaterials to overcome the shortcomings of existing biomaterials used as the bioinks, and make them suitable for various soft and hard tissue regeneration applications.
\end{abstract}

Keywords: 3D Bioprinting, bio-inks, biomaterials, nanomaterials, tissue engineering and regenerative medicine

\section{Introduction}

Since the beginning of the transplantation era, demand for organ has been increased and has overtaken the supply[1]. There is a subsequent waiting list for organ transplantation and it is increasing day by day. However, development of new technologies in biomedical engineering has helped to develop many potential new alternatives for transplant crisis[1]. Among these technologies exists 3D bioprinting which prints the organ with the help of bioprinters. Table 1 shows trend of bioprinted organ successfully transplanted into the living system. Bioprinting uses three dimensional deposition of cell laden biomaterials to create an organized structure with tissue appropriate architecture. This type of engineered organ can offer alternative to donor for organ transplantation and tissue printing could offer better clinical evaluation of therapeutic agents[2]. However efficiency of bioprinting depends on several parameters such as extruder, biocompatibility of material and remodeling of cells. To fulfill these requirements and to eliminate the drawbacks of conventional biomaterials use of nanophase biomaterials are employed by the use of nanotechnology. Nanotechnology is one of the most growing areas for current research and development in all technical disciplines. This obviously includes biomedical science and technology and even in this field the investigations cover a broad range of topics like bone, cartilage and other biomedical areas. Other biomedical areas includes polymer-based biomaterials, nanoparticle drug delivery, miniemulsion particles, electrospun nanofibers, imprint lithography, polymer blends and nanocomposites[3-5]. One of the emerging areas which is gaining attention is use of nanotechnology for 3D bioprinting. 3D bioprinting consists of bioink which is an integral part of bioprinting technology. It provides cells with protection from external mechanical stresses and supplies essential nutrients and oxygen, helping in excretion of waste and toxic compounds from the cells. Hence a highly efficient cell printing depends on a bioink which is been used during the printing process[6-11]. Moreover, a bio-ink should maintain 3D environment for the cells to grow effectively providing structural integrity and biocompatibility (noncytotoxic and allow cell attachment and proliferation)[12-14]. For these reasons, improvements in developing new bio-inks is considered as a major area of research in expanding cell printing processes[15,16]. In this development nanotechnology based bioinks plays a major role. Conventional bioinks consist of biomaterials which are classified as natural, synthetic, self assembled, hybrid, and nanostructured reinforced bioinks. These bioinks are used extensively for printing of bone/tissue constructs. The review mainly focusses on the use of nanomaterials into bioinks for 3D bioprinting. In this context biomaterials consisting of nanoparticles or nano biomaterials are 
taken into consideration and their use in 3D printing with the incorporation of cells making it as a bioinks enhancing the process of bioprinting. Further we will be looking at the applications of tissue engineering for various regenerative therapies. In the conclusion we will discuss some of the clinical updates on bioprinting along with the commercial aspects of bioprinting and some of the latest research such as magnetized biomaterial for $3 \mathrm{D}$ bio printing and theronostic applications.

\begin{tabular}{|l|l|c|}
\hline \multicolumn{1}{|c|}{ Year } & \multicolumn{1}{c|}{ Trend of organ printing and transplant } & Ref \\
\hline 1998 & $\begin{array}{l}\text { Canadian researchers create artificial blood vessels by wrapping sheets of cultured human cells into } \\
\text { tubes }\end{array}$ & [17] \\
\hline 1999 & $\begin{array}{l}\text { Luke Massella receives one of the first 3D-printed bladders thanks to the Wake Forest Institute for } \\
\text { Regenerative Medicine. It's a combination of 3D printed biomaterials and his own cells85 }\end{array}$ & [18] \\
\hline 2002 & $\begin{array}{l}\text { Early stage kidney prototype manufactured using microextrusion bioprinting at Wake Forest Institute for } \\
\text { Regenerative Medicine }\end{array}$ & [12] \\
\hline 2004 & Gabor Forgacs and his team develop multicellular spheroids for 3-D bioprinting & {$[19]$} \\
\hline 2010 & Wake Forest researchers bioprint skin directly onto injured mice to help heal burns & {$[20]$} \\
\hline 2013 & Princeton University researchers led by Michael C. McAlpinebioprint a working ear & {$[21]$} \\
\hline 2013 & Cornell University researchers led by Jonathan Butcher bioprint an artificial heart valve & [22] \\
\hline 2014 & Implementation of a multiarmbioprinter to integrate tissue fabrication with printed vasculature & {$[12]$} \\
\hline 2014 & Organovo releases 3-D printed liver tissue to aid in drug development. & {$[23]$} \\
\hline 2015 & 3D printed prosthetic hands & {$[24]$} \\
\hline 2016 & Rovotek implants 3D printed blood vessel in rhesus monkey & \\
\hline
\end{tabular}

\section{Table 1: Trend of organ printing}

\section{Basics Of 3D Bioprinting}

3D printing was first developed by Charles hull in 1984 by making three dimensional object using stereolithography [26]. 3D bioprinting started at around 1999 with the first 3D printed bladder made by the foreign institute for regenerative medicine and was successfully implanted in human body system[18].The process of 3D bioprinting focusses on creating cell patterns in a giving space using 3D printing technologies, where cell viability and function are maintained within the printed structure[27]. The process of 3D printing includes layer by layer deposition of biomaterials resulting into formation of tissue like structures which can be used for biomedical applications[12]. Bioprinting covers a broad range of biomaterials which contains both natural as well as synthetic materials. The overall process of bioprinting is completed in 3 steps which consist of pre-bioprinting, bioprinting and post-bioprinting. In pre-bioprinting designing a model suitable for printing with use of techniques like computed topography (CT) and magnetic resonance imaging (MRI) is practiced while in bioprinting the mixture of cells and nutrient are placed in a printer cartridge which prints the structures in a layer by layer approach to generate tissue like three dimensional structure and later it is differentiated into desired tissue by maintaining aseptic conditions[28]. Post-bioprinting process includes remodeling of tissue with the help of mechanical and chemical signals resulting into a well defined tissue construct[29]. Below figure 1 shows a schematic representation of bioprinting process.

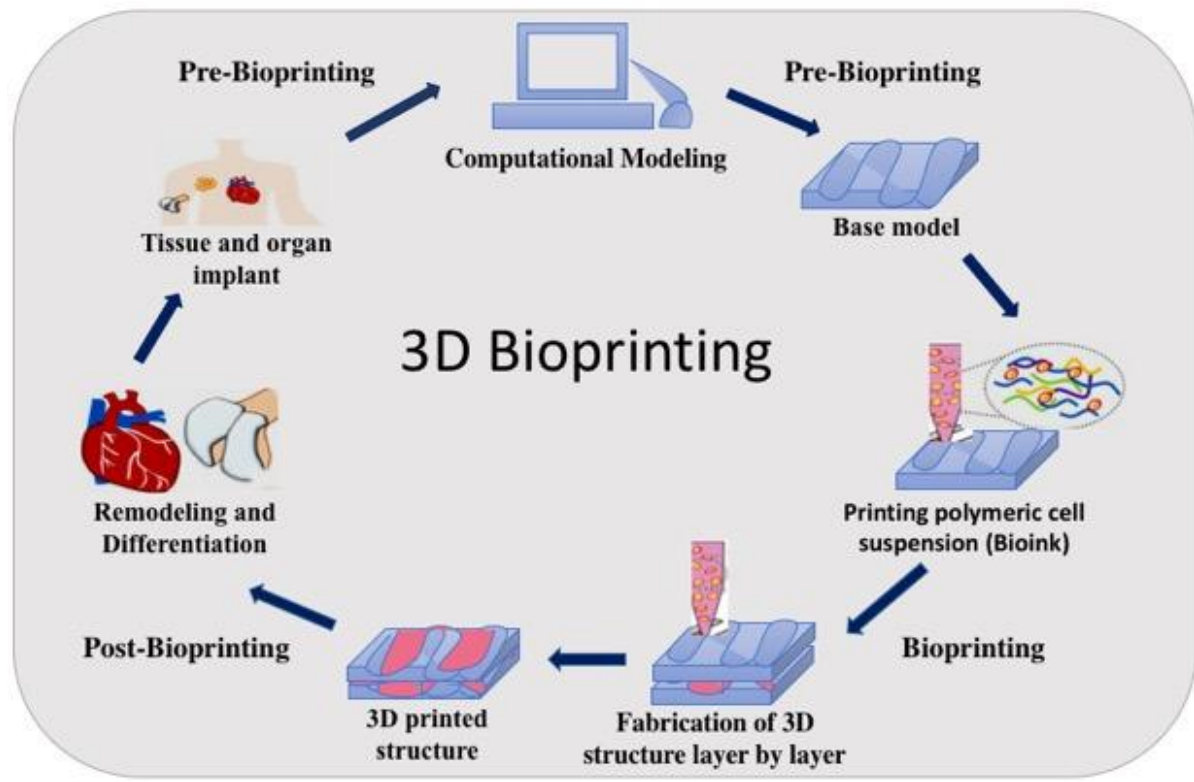

Figure 1: Schematic representation of 3D bioprinting 


\section{Designing Biomaterials For 3D Printing}

The advances in 3D printing technologies over the past 20 years have made these technologies suitable for many new fields. Among these fields are medical devices and tissue engineering in which 3D printing has gathered significant interest. 3D printing technology provides facility to fabricate patient-specific customized devices in short times for a lower cost making it perfect technology for personalized medicine. A wide range of biomaterials has been used as inks forming 3D structures with a wide range of size and stiffness[30][31]but most of industrial biomaterials lack biocompatibility, despite that also they can compete with traditional biomedical treatment. In this section we will discuss the material properties and these key features in developing biomaterial inks for 3D printing. There are very few biodegradable polymeric bioinks that have limited processability, mechanics and degradation. It can be said that hardly any biomaterial offers the ability to be functionalized. Currently biomaterials are used for space filling applications favoring basic cell function but with very less bioactivity. Therefore, the major obstacle for the coming years will be in creating novel biodegradable polymer inks with tunable properties. In case of ceramics-based inks the focus will be on controlling particle flow and powder size by surface modifications, and making it more efficient as binding materials. In comparison to ceramic and polymer inks, hydrogel inks are gaining much more attention and significant developments have already been made to design novel ink combinations. Developing nanobased bioinks is also getting attention which provides better processability, degradation, stiffness and ability to be functionalized. The detailed discussion on nanobased bioinks is discussed in coming context. It was seen that hydrogels consisting several molecules enable high resolution multimaterial printing of structure with cells [32]. Non-covalent cross-links results into self supporting structure with direct extrusion technique. Multimaterial bioinks also enabled low molecular weight polyimide based inks[33]. In addition, the fundamental design approach for ink design has evolved from single component to multicomponent inks consisting of both nano as well as macro materials, and from distinct cross-linking mechanism to complementary sequential crosslinking mechanisms (pre- or postprinting). The ultimate goal is to create self-supporting, cell-laden 3D scaffolds. Creating the hybrid constructs composed of biodegradable polymer inks with much softer cell-laden hydrogels inks will bring this technology one step closer to this goal[33].

\section{Nanoscale Biomaterials For 3D Printing}

Nanotechnology plays a key role in the synthesis of nanophase biomaterials. These biomaterials can either be used for 3D printing along with the cells called as bioinks or for other biomedical applications such as drug delivery, orthopedic implants and diagnostic application. Here we are discussing nanoscale biomaterials specifically used as bioinks for 3D printing. Bioinks are considered to be integral part of bioprinting which contains liquid cell suspension with printing cartridges and provides cells the environment which favors their growth and development. The cells remain in suspension within the cartridges till they are transferred to another cartridge containing liquid matrix material, resulting into binding of both cells and matrix with the help of various proteins and biological growth factors forming a bioscaffold which starts the regeneration process [34]. Additionally, bioinks protects cells from damage caused during printing process hence it's a kind of protective shield for cells when it is fabricated into biological constructs. Their basic function is to regenerate tissue on artificial surfaces. Several types of inks from different sources like natural, synthetic etc. are available commercially. An ideal nanoscale bioink should be nano range and consist of more than one biomaterial to get better printing efficiency. Nowadays nanoscale biomaterials are synthesized by blending nanoparticles in the existing material. Previously due to lack of technology, development of bioinks was restricted to some extent, but with advancement in research, new and effective bioinks are being developed which is changing the phase of bioprinting industry. An ideal nano bioink candidate should (1) have enough mechanical strength, rigidity and shape fidelity to form scaffold. (2) Should be tuned properly in order to favor extrusion, (3) form scaffolds that mimics the native cellular microenvironment, (4) exhibit biocompatibility, (5) be amenable to chemical modifications to tailor the cellular microenvironment, and (6) be capable of large scale synthesis with minimal batch-to-batch variation. When talking in terms of applicability, this technology is useful in the field of skin repair, also small injuries like lacerations and burns can be easily repaired with the use of bioinks. Although initial developments of bioinks began with skin regeneration, the technology went further to also incorporate bone and cartilage. This makes bioinks a total regenerative technology. It might seem like fiction now, but in the last few decades, ground breaking research was carried out for regeneration and replacement of all bodily tissues. As of now, spray technology for tissue regeneration has been developed which is certainly changing the perspective of regenerative medicine. All that must be accomplished now is the rapid regeneration and seemingly impossible science fiction becomes reality. That is the technology of nanoscale bioscaffolds and bioinks technology[35]. 


\section{Application Of 3D Printed Nanoscale Biomaterials In Tissue Engineering And Regenerative Medicine}

Nanomaterials offer promising new alternatives as they possesssimilar dimensions to components of natural tissues, such as proteins. Clearly, in our bodies regeneration of tissues are governed by nanoscale events[36]. It is widely regarded that surface modification of implants to posses biologically inspired nanometer features undoubtedly will play a key role in development of next generation orthopedic materials. Similar to creating micron roughness, results of bone formation on implant surface with nanometer roughness values appear to be universal and better than on micron rough surfaces. In fact, when compared with conventional materials (or materials with micron grain sizes), several studies have reported improved osteogenic integration on nanostructured surfaces created from a wide range of chemistries, including ceramics, metal, polymers and composites[37]. As a template for cell growth and tissue formation, a porous scaffold is one of the most important components for tissue engineering. However, whilst a variety of synthetic polymers (e.g., poly(L lactide) (PLLA), poly(lactic- co - glycolic acid) (PLGA)), and natural polymers (e.g., collagen, alginate, agarose) have been used to fabricate the porous scaffolds, several challenges remain, including the limited available cell density and the active controllability of the cell growth. Nanoscale hydrogel based scaffolds have the potential to address these challenges[38]. In this case to enhance the applicability as well as properties of hydrogels many researchers have incorporated various nanoparticles into the existing biomaterials for various biomedical applications such asGuifangGao and his colleagues developed a bioactive nanoparticles stimulated bone tissue formation in bioprinted three dimensional scaffold using human mesenchymal stem cells. The study was carried out to check bioactive ceramic nanoparticles for osteogenesis of bone marrow derived mesenchymal stem cells (hMSCs) in poly(ethylene glycol) dimethacrylate (PEGDMA) scaffold. Stem cells suspended in PEGDMA were co-printed with nanoparticles of bioactive glass (BG) and hydroxyapatite (HA) under simultaneous polymerization so the printed substrates were delivered with highly accurate placement in threedimensional (3D) locations (Figure 2A). Cell viability was found to be around 86\% (Figure 2B) and compressive modulus of $358.91 \mathrm{kPa}$ after 21 days among all the groups. There was highest alkaline phosphatase activity observed in PEG-HA group which was verified with gene expression by quantitative PCR. Masson's trichromestaining also showed the most collagen deposition in PEG-HA scaffold. Therefore, hydroxyapatite is more effective comparing to BG for hMSCsosteogenesis in bioprinted bone constructs[39].

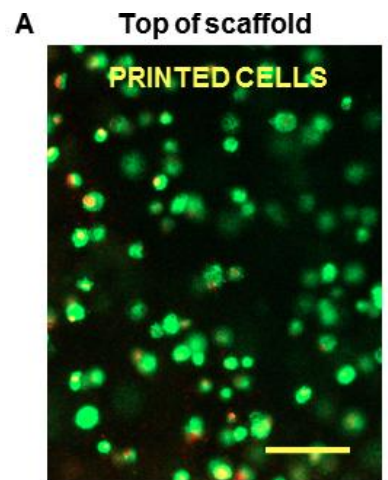

Bottom of scaffold
Top of scaffold

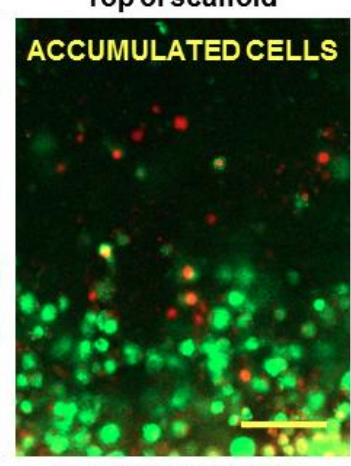

Bottom of scaffold
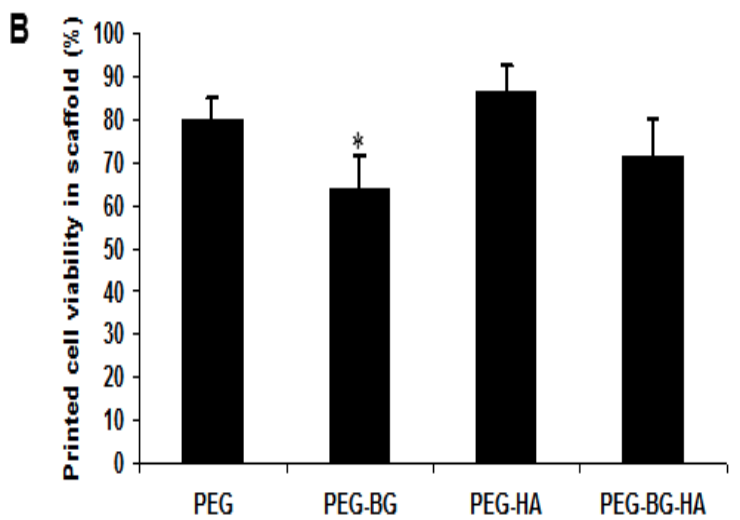

Figure 2:Printed hMSCs in 3D hydrogel and cell viability. (A) Evenly distributed hMSCs in 3D PEG hydrogel with simultaneous photopolymerization(Left). The cells were accumulated to the bottom of the scaffold instead of their originally deposited locations due to gravity in the non-printed constructs (Right). Scale bar $=100 \mu \mathrm{m}$. (B) Cell viability in PEG, PEG-BG, PEG-HA, and PEG-BG-HA scaffolds 24 hours after printing. The cell viability in PEG-BG scaffold was considerably lower than those in other scaffolds. Asterisks indicate statistical significance between groups $(* \mathbf{p}<0.05)(\mathrm{n}=3)[39]$.

This type of biomaterials may be investigated as a potential nanocomposite implant for tissue engineering.Adding to this,recently a group of researchers studied a bioink that combines the outstanding shear thinning properties of nanofibrillated cellulose (NFC) with the fast cross-linking ability of alginate was formulated for the 3D bioprinting of living soft tissue with cells. Printability was evaluated with concern to printer parameters and shape fidelity. The shear thinning behavior of the tested bioinks enabled printing of both 2D gridlike structures as well as 3D constructs. Furthermore, anatomically shaped cartilage structures, such as a human ear and sheep meniscus, were 3D printed using MRI and CT images as blueprints. (Figure 3) Human chondrocytes bioprinted in the noncytotoxic, nanocellulose-based bioink exhibited a cell viability of $73 \%$ and $86 \%$ after 1 and 7 days of 3D culture, On the basis of these results, it can be concluded that the nanocellulosebased bioink is a suitable hydrogel for 3D bioprinting with living cells. This study demonstrates the potential use of nanocellulose for 3D bioprinting of living tissues and organs[40]. 


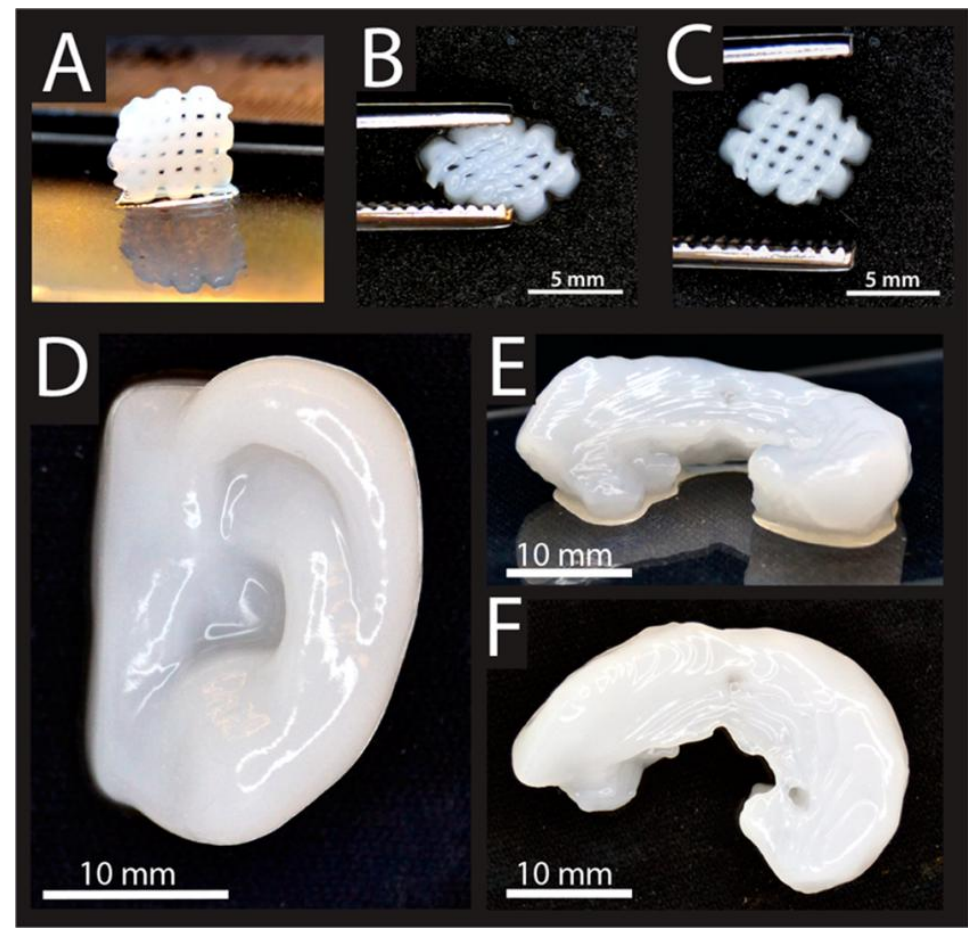

Figure 3: (A) 3D printed small grids $\left(7.2 \AA \sim 7.2 \mathrm{~mm}^{2}\right)$ with Ink8020 after cross-linking. (B) Deformation of grid while squeezing, (C) restored grid after squeezing. (D) 3D printed human ear and (E and F) sheep meniscus with Ink8020. Side view (E) and top view (F) of meniscus[40].

Few of the nano scale biocomposites which are already used for tissue engineering as well as bioprinting of tissue constructsare described in table 2 below. These biocompositesare composed of nanophasematerials that enhance the properties of existing bioinks.

\begin{tabular}{|c|c|c|c|c|c|c|c|}
\hline Nano materials & Type of cells & $\begin{array}{l}\text { Mechanism of } \\
\text { crosslinking }\end{array}$ & $\begin{array}{l}\text { Shape } \\
\text { fidelity }\end{array}$ & $\begin{array}{l}\text { Printable } \\
\text { size }\end{array}$ & $\begin{array}{l}\text { Cell } \\
\text { compatibility }\end{array}$ & Applications & $\begin{array}{l}\text { Refer } \\
\text { ences }\end{array}$ \\
\hline Collagen-nHAp & $\begin{array}{l}\text { hBMSc, } \\
\text { osteoblast, } \\
\text { chondrocytes }\end{array}$ & UV-irradiation & High & - & $75-95 \%$ & Organ culture & $\begin{array}{l}{[41,4} \\
2]\end{array}$ \\
\hline $\begin{array}{l}\text { Hyaluronic acid- } \\
\text { PCL-PLGA }\end{array}$ & MC3T3-E1 & thermally & High & $400 \mu \mathrm{m}$ & $80-95 \%$ & $\begin{array}{l}\text { Liver tissue } \\
\text { engineering }\end{array}$ & [43] \\
\hline $\begin{array}{l}\text { PCL-Halloysite } \\
\text { NC }\end{array}$ & hBMSc & ionic & Medium & $15.15 \mathrm{~mm}$ & $140-160 \%$ & $\begin{array}{l}\text { Bone tissue } \\
\text { engineering }\end{array}$ & {$[44]$} \\
\hline $\begin{array}{l}\text { PCL-Nano silica- } \\
\text { nHAp }\end{array}$ & hBMSc & ionic & Strong & $10 \mathrm{cms}$ & $30-85 \%$ & $\begin{array}{l}\text { Osteogenic } \\
\text { regeneration }\end{array}$ & [45] \\
\hline PLGA-nHAp & hBMSc & ionic & Medium & $20 \mathrm{cms}$ & $70-80 \%$ & $\begin{array}{l}\text { Hard tissue } \\
\text { regeneration }\end{array}$ & {$[46]$} \\
\hline PEG-nHAp & $\begin{array}{l}\text { MC3T3-E1 } \\
\text { preosteoblast }\end{array}$ & $\begin{array}{l}\text { Photo cross } \\
\text { linker }\end{array}$ & Medium & $5 \mathrm{~mm}$ & $60-80 \%$ & $\begin{array}{l}\text { Orthopaedic } \\
\text { applications }\end{array}$ & [47] \\
\hline $\begin{array}{l}\text { Nano silicate+ } \\
\text { GelMA+ nHAp }\end{array}$ & $\begin{array}{l}\text { MC3T3 } \\
\text { preosteoblasts }\end{array}$ & UV crosslinked & High & $400 \mu \mathrm{m}$ & $60-70 \%$ & $\begin{array}{l}\text { Bone tissue } \\
\text { engineering }\end{array}$ & [48] \\
\hline $\begin{array}{l}\text { PEGDA+ } \\
\text { alginate+ } \\
\text { nanosilica }\end{array}$ & hBMSc & Covalent & High & $500 \mu \mathrm{m}$ & $75-85 \%$ & $\begin{array}{l}\text { Tough hydrogels } \\
\text { for tissue } \\
\text { engineering }\end{array}$ & [49] \\
\hline Gelatin+nHAp & MG 63 & Thermally & High & $90-100 \mathrm{~nm}$ & $70-80 \%$ & $\begin{array}{l}\text { Tissue engineering } \\
\text { scaffold }\end{array}$ & {$[50]$} \\
\hline $\begin{array}{l}\text { Carboxymethylate } \\
\text { d-Periodate } \\
\text { Oxidized } \\
\text { Nanocellulose }\end{array}$ & - & Ionic & Low & $25 \times 6 \mathrm{~mm}$ & - & Wound dressing & [51] \\
\hline AuNP-sECMs & Fibroblast & Covalent & Medium & $1 \mathrm{x} 1 \mathrm{~cm}$ & $95 \%$ & Tissue engineering & {$[2]$} \\
\hline $\begin{array}{l}\text { PCL-alginate } \\
\text { nanofibers }\end{array}$ & C20A4 & Ionic & High & $6 \times 6 \times 2 \mathrm{~mm}$ & $70 \%$ & Tissue construct & {$[52]$} \\
\hline PEGDA+ nHAp & hBMSCs & UV crosslinking & High & $35 \times 35 \times 5 \mathrm{~mm}$ & $80 \%$ & $\begin{array}{l}\text { Osteochondral } \\
\text { regeneration }\end{array}$ & {$[53]$} \\
\hline
\end{tabular}

(nHAp: Nanohydroxyapatite, PCL: Polycaprolactone, PLGA: Poly(lactic-co-glycolic acid)NC: Nanoclay, GelMA: Gelatin Methacrylate, PEGDA: Poly(ethylene glycol) Diacrylate, Au-NP: Gold Nanoparticles, ECM: Extra Cellular Matrix)

Table 2: Nanoscale biomaterial for bioprinting applications. 


\section{Concluding Remarks}

In summary we can say that nanophase composites havea great potential as bioinks in 3D printing for tissue regeneration. The use of nanotechnology for synthesizing nanophase composite is practiced now a days and it has shown significantly good results in terms of tissue fabrication. The nano materials synthesized by using more than onematerial are much better than the conventional biomaterial and commercially usedmaterials for industrial applications can alsoprovide a unique opportunity for translation of these materials into biomedical field. Multifunctional approaches integrating mechanical, physical, and chemical factors stimulate quick cellular response by activating several pathways simultaneously. A major future step for bio inspired regenerative medicine research is parallel, three-dimensional and sequential control over stem-cell development through polymeric and nanomaterial manipulation. Various smart hydrogels that are responsive to external stimuli (e.g., temperature, $\mathrm{pH}$, light, charge, pressure) in a physiological range have great potential in biomedical applications such as drug delivery and release. However, two main limitations exist: 1) the response time of these stimulisensitive hydrogels is long; and 2) hydrogels with more biocompatibility and biodegradability are required[54]. despite the challenges that lie ahead, significant evidence now exist demonstrating that nanophase materials represents an important growing area of research that may improve bonding between an implant and the surrounding bone. Two recent achievements include the growing of human cells using 3D bioprinting techniques without the use of scaffold-like devices, and the creation of liver tissue in three-dimensions for drug testing purposes in clinical trials. This is one of the growing steps towards commercialization of 3D bioprinting. Even nanophase biomaterials provide opportunity for improving the implant efficacy by using advanced printing technique.

\section{References}

[1]. Armando Salim Munoz-Abraham \& Manuel I. Rodriguez-Davalos, A.B.\& B.W.\& J.P.G.\& D.C. Mulligan, 3D Printing of Organs for Transplantation: Where AreWe and Where Are We Heading?, Tissue Eng. Regen. curr trans (2016) 1-7.

[2]. B. Aleksander Skardal, J. Zhang, L. McCoard, S. Oottamasathien, G.D. Prestwich, G.D. Prestwich, A. Skardal, J. Zhang, L. McCoard, S. Oottamasathien, Dynamically Crosslinked Gold Nanoparticle - Hyaluronan Hydrogels, Adv. Mater. 22 (2010) 47364740. doi:10.1002/adma.201001436.

[3]. J. Mark, C. Jiang, M. Tang, Simultaneous curing and filling of elastomers, Macromolecules. 17 (1984) $2613-2616$. doi: $10.1021 / \mathrm{ma} 00142 \mathrm{a} 026$.

[4]. H. Zou, S. Wu, J. Shen, Polymer/silica nanocomposites: preparation, characterization, properties, and applications., Chem. Rev. 108 (2008) 3893-3957. doi:10.1021/cr068035q

[5]. I.Y. Jeon, J.B. Baek, Nanocomposites derived from polymers and inorganic nanoparticles, Materials (Basel). 3 (2010) $3654-3674$. doi:10.3390/ma3063654.

[6]. A.C. Jen, M.C. Wake, A.G. Mikos, Review: Hydrogels for cell immobilization, Biotechnol. Bioeng. 50 (1996) $357-364$. doi:10.1002/(SICI)1097-0290(19960520)50:4<357::AID-BIT2>3.0.CO;2-K.

[7]. W.C. Wilson, T. Boland, Cell and organ printing 1: protein and cell printers., Anat. Rec. A. Discov. Mol. Cell. Evol. Biol. 272 (2003) 491-6. doi:10.1002/ar.a.10057.

[8]. C. Fischbach, R. Chen, T. Matsumoto, T. Schmelzle, J.S. Brugge, P.J. Polverini, D.J. Mooney, Engineering tumors with 3D scaffolds., Nat. Methods. 4 (2007) 855-860. doi:10.1038/nmeth1085.

[9]. D.L. Cohen, E. Malone, H. Lipson, L.J. Bonassar, Direct freeform fabrication of seeded hydrogels in arbitrary geometries., Tissue Eng. 12 (2006) 1325-1335. doi:10.1089/ten.2006.12.1325.

[10]. B. Derby, Bioprinting: inkjet printing proteins and hybrid cell-containing materials and structures, J. Mater. Chem. 18 (2008) 5717. doi: $10.1039 / \mathrm{b} 807560 \mathrm{c}$.

[11]. D.L. Cohen, W. Lo, A. Tsavaris, D. Peng, H. Lipson, L.J. Bonassar, Increased Mixing Improves Hydrogel Homogeneity and Quality of Three-Dimensional Printed Constructs, Tissue Eng. 17 (2011) 239-248. doi:10.1089/ten.tec.2010.0093.

[12]. S. V Murphy, A. Atala, 3D bioprinting of tissues and organs., Nat. Biotechnol. 32 (2014) 773-785. doi:10.1038/nbt.2958

[13]. K. Pataky, T. Braschler, A. Negro, P. Renaud, M.P. Lutolf, J. Brugger, Microdrop printing of hydrogel bioinks into 3D tissue-like geometries, Adv. Mater. 24 (2012) 391-396. doi:10.1002/adma.201102800.

[14]. V. Mironov, V. Kasyanov, R.R. Markwald, Organ printing: From bioprinter to organ biofabrication line, Curr. Opin. Biotechnol. 22 (2011) 667-673. doi:10.1016/j.copbio.2011.02.006.

[15]. Y. Zhang, Y. Yu, H. Chen, I.T. Ozbolat, Characterization of printable cellular micro-fluidic channels for tissue engineering., Biofabrication. 5 (2013) 25004. doi:10.1088/1758-5082/5/2/025004.

[16]. A.L. Rutz, K.E. Hyland, A.E. Jakus, W.R. Burghardt, R.N. Shah, A multimaterial bioink method for 3D printing tunable, cellcompatible hydrogels, Adv. Mater. 27 (2015) 1607-1614. doi:10.1002/adma.201405076.

[17]. N. L’Heureux, S. Pâquet, R. Labbé, L. Germain, F.A. Auger, A completely biological tissue-engineered human blood vessel., FASEB J. 12 (1998) 47-56. doi:0892-6638/97/0012-0047.

[18]. A. Atala, Tissue engineering of human bladder, Br. Med. Bull. 97 (2011) 81-104. doi:10.1093/bmb/ldr003.

[19]. K. Jakab, A. Neagu, V. Mironov, R.R. Markwald, G. Forgacs, Engineering biological structures of prescribed shape using selfassembling multicellular systems, Proc. Natl. Acad. Sci. 101 (2004) 2864-2869. doi:10.1073/pnas.0400164101.

[20]. K.W. Binder, W. Zhao, D. Dice, A. Atala, J.J. Yoo, In situ bioprinting of the skin for burns., J. Am. Coll. Surg. 211 (2010) S76. doi:10.1016/j.actbio.2014.09.023.

[21]. M.S. Mannoor, Z. Jiang, T. James, Y.L. Kong, K.A. Malatesta, W.O. Soboyejo, N. Verma, D.H. Gracias, M.C. McAlpine, 3D printed bionic ears, Nano Lett. 13 (2013) 2634-2639. doi:10.1021/n14007744.

[22]. B. Duan, E. Kapetanovic, L.A. Hockaday, J.T. Butcher, Three-dimensional printed trileaflet valve conduits using biological hydrogels and human valve interstitial cells, Acta Biomater. 10 (2014) 1836-1846. doi:10.1016/j.actbio.2013.12.005.

[23]. L. Mearian, The first 3D printed organ -- a liver -- is expected in 2014, Comput. World. (2014).

[24]. J. Schull, Bioprinting: The new frontier in medicine that's not science fiction, CNBC. (2015).

[25]. Sarah Saunders, Biotechnology Company Sichuan Revotek Successfully Implants Live 3D Printed Blood Vessels in Rhesus Monkeys, 3D Print. Ind. (2016). 
[26]. D.T. Pham, S.S. Dimov, Rapid prototyping and rapid tooling - the key enablers for rapid manufacturing, Proc. Inst. Mech. Eng. Part C J. Mech. Eng. Sci. 217 (2003) 1-23. doi:10.1243/095440603762554569.

[27]. Y.J. Seol, H.W. Kang, S.J. Lee, A. Atala, J.J. Yoo, Bioprinting technology and its applications, Eur. J. Cardio-Thoracic Surg. 46 (2014) 342-348. doi:10.1093/ejcts/ezu148.

[28]. A. Shafiee, A. Atala, Printing Technologies for Medical Applications, Trends Mol. Med. 22 (2016) $254-265$. doi:10.1016/j.molmed.2016.01.003.

[29]. K. Harmon, A Sweet Solution for Replacing Organs., Sci. Am. 308 (2013) 54-55. doi:10.1038/scientificamerican0413-54

[30]. D.B. Kolesky, R.L. Truby, A.S. Gladman, T.A. Busbee, K.A. Homan, J.A. Lewis, 3D bioprinting of vascularized, heterogeneous cell-laden tissue constructs, Adv. Mater. 26 (2014) 3124-3130. doi:10.1002/adma.201305506.

[31]. G. Villar, A.D. Graham, H. Bayley, A tissue-like printed material., Science. 340 (2013) 48-52. doi:10.1126/science.1229495.

[32]. C.B. Highley, C.B. Rodell, J.A. Burdick, Direct 3D Printing of Shear-Thinning Hydrogels into Self-Healing Hydrogels, Adv. Mater. 27 (2015) 5075-5079. doi:10.1002/adma.201501234.

[33]. M. Guvendiren, J. Molde, R.M.D. Soares, J. Kohn, Designing Biomaterials for 3D Printing, ACS Biomater. Sci. Eng. 2 (2016) 1679-1693. doi:10.1021/acsbiomaterials.6b00121.

[34]. V. Mironov, N. Reis, B. Derby, Review: Bioprinting: A Beginning, Tissue Eng. 12 (2006) 631-634. doi:10.1089/ten.2006.12.631.

[35]. J. Groll, T. Boland, T. Blunk, J.A. Burdick, D.-W. Cho, P.D. Dalton, B. Derby, G. Forgacs, Q. Li, V.A. Mironov, L. Moroni, M. Nakamura, W. Shu, S. Takeuchi, G. Vozzi, T.B.F. Woodfield, T. Xu, J.J. Yoo, J. Malda, Biofabrication: reappraising the definition of an evolving field., Biofabrication. 8 (2016) 13001. doi:10.1088/1758-5090/8/1/013001.

[36]. M.M. Stevens, J.H. George, Exploring and engineering the cell surface interface., Science. 310 (2005) $1135-1138$. doi:10.1126/science.1106587.

[37]. T.J. Webster, C. Ergun, R.H. Doremus, R.W. Siegel, R. Bizios, Enhanced osteoclast-like cell functions on nanophase ceramics, Biomaterials. 22 (2001) 1327-1333. doi:10.1016/S0142-9612(00)00285-4.

[38]. Y. Li, G. Huang, X. Zhang, B. Li, Y. Chen, T. Lu, T.J. Lu, F. Xu, Magnetic hydrogels and their potential biomedical applications, Adv. Funct. Mater. 23 (2013) 660-672. doi:10.1002/adfm.201201708.

[39]. G. Gao, A.F. Schilling, T. Yonezawa, J. Wang, G. Dai, X. Cui, Bioactive nanoparticles stimulate bone tissue formation in bioprinted three-dimensional scaffold and human mesenchymal stem cells, Biotechnol. J. 9 (2014) 1304-1311. doi:10.1002/biot.201400305.

[40]. G.P. Markstedt K, Mantas A, Tournier I, Martínez Ávila H, Hägg D, 3D Bioprinting Human Chondrocytes with NanocelluloseAlginate Bioink for Cartilage Tissue Engineering Applications, Biomacromolecules. 16 (2015) 1489-96.

[41]. C. Du, F.Z. Cui, X.D. Zhu, K. De Groot, Three-dimensional nano-HAp/collagen matrix loading with osteogenic cells in organ culture, J. Biomed. Mater. Res. 44 (1999) 407-415. doi:10.1002/(SICI)1097-4636(19990315)44:4<407::AID-JBM6>3.0.CO;2-T.

[42]. H.H. Lu, S.F. El-Amin, K.D. Scott, C.T. Laurencin, Three-dimensional, bioactive, biodegradable, polymer-bioactive glass composite scaffolds with improved mechanical properties support collagen synthesis and mineralization of human osteoblast-like cells in vitro., J. Biomed. Mater. Res. A. 64 (2003) 465-474. doi:10.1002/jbm.a.10399.

[43]. J.P. Jin-Hyung Shim, Jong Young Kim, Min Park, and D.-W. Cho, Development of a hybrid scaffold with synthetic biomaterials and hydrogel using solid freeform fabrication technology, Biofabrication. 3 (2011).

[44]. G. Nitya, G.T. Nair, U. Mony, K.P. Chennazhi, S. V. Nair, In vitro evaluation of electrospun PCL/nanoclay composite scaffold for bone tissue engineering, J. Mater. Sci. Mater. Med. 23 (2012) 1749-1761. doi:10.1007/s10856-012-4647-x.

[45]. N. Ganesh, R. Jayakumar, M. Koyakutty, U. Mony, S. V. Nair, Embedded Silica Nanoparticles in Poly(Caprolactone) Nanofibrous Scaffolds Enhanced Osteogenic Potential for Bone Tissue Engineering, Tissue Eng. Part A. 18 (2012) 1867-1881. doi:10.1089/ten.tea.2012.0167.

[46]. T. Chae, H. Yang, F. Ko, T. Troczynski, Bio-inspired dicalcium phosphate anhydrate/poly(lactic acid) nanocomposite fibrous scaffolds for hard tissue regeneration: In situ synthesis and electrospinning, J. Biomed. Mater. Res. - Part A. 102 (2014) 514-522. doi:10.1002/jbm.a.34715.

[47]. A.K. Gaharwar, S.A. Dammu, J.M. Canter, C.J. Wu, G. Schmidt, Highly extensible, tough, and elastomeric nanocomposite hydrogels from poly(ethylene glycol) and hydroxyapatite nanoparticles, Biomacromolecules. 12 (2011) 1641-1650. doi: $10.1021 / \mathrm{bm} 200027 \mathrm{z}$

[48]. J.R. Xavier, T. Thakur, P. Desai, M.K. Jaiswal, N. Sears, E. Cosgriff-Hernandez, R. Kaunas, A.K. Gaharwar, Bioactive nanoengineered hydrogels for bone tissue engineering: A growth-factor-free approach, ACS Nano. 9 (2015) 3109-3118. doi:10.1021/nn507488s.

[49]. S. Hong, D. Sycks, H.F. ai Chan, S. Lin, G.P. Lopez, F. Guilak, K.W. Leong, X. Zhao, 3D Printing: 3D Printing of Highly Stretchable and Tough Hydrogels into Complex, Cellularized Structures, Adv. Mater. 27 (2015) 4034. doi:10.1002/adma.201570182.

[50]. H.W. Kim, J.C. Knowles, H.E. Kim, Hydroxyapatite and gelatin composite foams processed via novel freeze-drying and crosslinking for use as temporary hard tissue scaffolds, J. Biomed. Mater. Res. - Part A. 72 (2005) 136-145. doi:10.1002/jbm.a.30168.

[51]. A. Rees, L.C. Powell, G. Chinga-Carrasco, D.T. Gethin, K. Syverud, K.E. Hill, D.W. Thomas, 3D Bioprinting of Carboxymethylated-Periodate Oxidized Nanocellulose Constructs for Wound Dressing Applications, Biomed Res. Int. 2015 (2015) 1-7. doi:10.1155/2015/925757.

[52]. W. Schuurman, V. Khristov, M.W. Pot, P.R. van Weeren, W.J. a Dhert, J. Malda, Bioprinting of hybrid tissue constructs with tailorable mechanical properties., Biofabrication. 3 (2011) 21001. doi:10.1088/1758-5082/3/2/021001.

[53]. N.J. Castro, R. Patel, L.G. Zhang, Design of a Novel 3D Printed Bioactive Nanocomposite Scaffold for Improved Osteochondral Regeneration, Cell. Mol. Bioeng. 8 (2015) 416-432. doi:10.1007/s12195-015-0389-4

[54]. G. Bayramoglu, B. Altintas, M.Y. Arica, Immobilization of glucoamylase onto polyaniline-grafted magnetic hydrogel via adsorption and adsorption/cross-linking, Appl. Microbiol. Biotechnol. 97 (2013) 1149-1159. doi:10.1007/s00253-012-3999-y. 